\title{
To close or not to close arteriovenous fistulas in kidney allograft recipients: that is the question
}

Letter to the Editor The controversial issue of arteriovenous (AV) fistula closure after successful kidney transplantation is important and efforts should be made to determine appropriate decisions in these cases. Głowiński et al. ${ }^{1}$ took this challenge comparing 9 patients with patent fistulas and 9 patients in whom the fistulas occluded spontaneously or were surgically closed post transplantation. After a 3-month follow-up, the authors did not find differences between the groups in terms of a change in the left ventricular (LV) diastolic diameter, muscle thickness, myocardial mass, or ejection fraction. It should be stated, however, that hardly any conclusion regarding the effect of fistula closure on the cardiovascular system can be made from these data. Taking into account limited precision of the echocardiographic evaluation of the measured parameters, the study group was too small to observe any statistical difference, particularly after such a short follow-up. Despite these limitations, the authors themselves point out that there were favorable changes in the LV diastolic diameter and the LV mass index (LVMI) after fistula ligation that reached borderline significance $(P=0.08$ for LVMI). Moreover, despite similar baseline echocardiographic parameters, there was a significant difference in the LV diastolic diameter between the groups at the end of follow-up in favor of the patients who underwent fistula ligation $(P=0.026)$.

We should also clearly point out that the development of LV hypertrophy, dilatation, and systolic dysfunction may take years rather than months. Echocardiographic tissue Doppler measurements could have given more information on cardiac function in this study. Unfortunately, although suggested by the caption of table $2,{ }^{1}$ no Doppler data were presented. Moreover, it would be important to know what was the flow in patent fistulas (some of them could be stenosed or partially thrombosed).

Since the evaluation methods of cardiac structure and function applied in the study were basic, the authors could also consider using other tests to better assess changes in the circulatory system caused over time by patent AV fistulas. On one hand, the evaluation of LV function with magnetic resonance imaging or even computed tomography could provide more insight into the structure of the myocardium. ${ }^{2}$ On the other hand, the use of stress testing (preferably spiroergometry) could give more objective details on the functional status and prognosis of the patients. ${ }^{3}$

We fully agree with the authors admitting the paper had significant limitations. We keep the fingers crossed hoping the study will recruit more patients and will be continued with a longer follow-up. Recognition of the prognostic factors determining the indications for AV fistula closure in kidney allograft recipients still remains a significant challenge.

Correspondence to: Grzegorz Gajos, MD, PhD, Andrzej Gackowski, MD, PhD, Klinika Choroby Wieńcowej, Instytut Kardiologii, Uniwersytet Jagielloński, Collegium Medicum, ul. Prądnicka 80, 31-202 Kraków, Poland, phone/ fax: +48-12-633-67-44, e-mail: dr.gajos@gmail.com; agackowski@szpitaljp2.krakow.pl.

\section{REFERENCES}

1 Głowiński J, Małyszko J, Głowińska I, Myśliwiec M. To close or not to close: fistula ligation and cardiac function in kidney allograft recipients. Pol Arch Med Wewn. 2012; 122: 348-352.

2 Krzych ŁJ. Assessment of left ventricular function with the use of computed tomography and magnetic resonance in patients with low ejection fraction scheduled for coronary artery bypass grafting: a preliminary study Pol Arch Med Wewn. 2012; 122: 398-405.

3 Sorajja P, Allison T, Hayes C, Nishimura RA, et al. Prognostic utility of metabolic exercise testing in minimally symptomatic patients with obstructive hypertrophic cardiomyopathy. Am J Cardiol. 2012; 109: 1494-1498. 
